Gut and Liver, Vol. 11, No. 5, September 2017, pp. 590-603

\title{
Combination Therapy for Chronic Hepatitis B: Current Updates and Perspectives
}

\author{
Tung-Hung Su $\mathrm{u}^{1,2}$ and Chun-Jen Liu ${ }^{1,2,3}$ \\ ${ }^{1}$ Department of Internal Medicine, ${ }^{2}$ Hepatitis Research Center, National Taiwan University Hospital, and ${ }^{3}$ Graduate Institute of Clinical \\ Medicine, National Taiwan University College of Medicine, Taipei, Taiwan
}

Nucleos(t)ide analogues (NUCs) and interferon have been used for several decades to treat chronic hepatitis B; however, the therapeutic response remains unsatisfactory. Although NUC therapy exhibits potent on-treatment viral suppression, frequent off-therapy virological relapses suggest an indefinite treatment course. Interferon modulates the innate and adaptive antiviral immune responses and thus increases the chance of viral eradication. Interferon therapy has the advantage of a finite duration, absence of drug resistance, and durable posttreatment responses. Therefore, the combination of NUCs and interferon can theoretically facilitate a synergistic therapeutic effect. This paper summarizes the current strategies of various combination therapies into three categories: the simultaneous "dual" strategy, sequential combination "add-on" strategy, and "switch" strategy. Generally, dual therapy exhibits greater on-treatment and off-therapy viral suppression and lower drug resistance compared with NUC monotherapy. Compared with interferon monotherapy, dual therapy has greater on-treatment viral suppression but shows no difference in off-therapy sustained virological responses. Specific add-on or switch strategies provide promising on-treatment efficacy in select patients. Pretreatment or on-treatment quantitative hepatitis $B$ surface antigen and e antigen are predictive for the treatment efficacy of combination therapy. The optimal schedule of combination regimens and individualized therapy remain to be comprehensively evaluated. (Gut Liver 2017;11:590603)

Key Words: Nucleos(t)ide analogue; Interferons; Dual; Addon; Switch

\section{INTRODUCTION}

Chronic hepatitis B virus (HBV) infection is a global health problem, with an estimated 240 million chronic hepatitis B (CHB) patients worldwide. Subsequent cirrhosis, hepatocellular carcinoma (HCC), and death are major risks for chronic HBV carriers. It is critical to develop treatment strategies to halt disease progression and ultimately eradicate CHB.

The current therapy for CHB employs nucleos(t)ide analogues (NUCs) and interferon (IFN). NUCs are viral polymerases and reverse transcriptase inhibitors that can efficiently suppress HBV viral replication, resulting in rapid HBV DNA reduction. Because NUCs do not target covalently closed circular DNA (cccDNA) transcription, NUCs can only slightly reduce the circulating hepatitis B e antigen (HBeAg) and hepatitis B surface antigen (HBsAg). Prolonged therapy with potent NUCs with the smallest drug resistance profiles can achieve long-term viral suppression and halt disease progression. ${ }^{1}$ Oral administration, few side effects, and high rates of on-treatment virological responses are the advantages of NUC therapy; however, the risk of drug resistance, long-term safety, and indefinite duration of therapy remain major concerns for NUCs. ${ }^{2}$

IFN-based therapy has both direct antiviral and immunomodulatory effects. Previous in vitro and in vivo studies have shown that IFN prevents the formation of replication-competent pregenomic RNA-containing HBV capsids, or otherwise accelerates their degradation, thereby inhibiting HBV replication., ${ }^{3,4}$ One recent study found that IFN- $\alpha$ inhibits HBV replication by reducing the transcription of pregenomic RNA and subgenomic RNA from the HBV cccDNA minichromosome, both in cultured cells with HBV replication and in HBV-infected mice with humanized livers. Administration of IFN- $\alpha$ results in cccDNA-bound histone hypoacetylation and active recruitment

Correspondence to: Chun-Jen Liu

Graduate Institute of Clinical Medicine, National Taiwan University College of Medicine, 1 Chang-Te Street, Taipei 10002, Taiwan

Tel: +886-2-23123456 (ext. 67503), Fax: +886-2-23825962, E-mail: cjliu@ntu.edu.tw

Received on April 25, 2016. Revised on June 30, 2016. Accepted on July 2, 2016. Published online May 12,2017

pISSN 1976-2283 eISSN 2005-1212 https://doi.org/10.5009/gnl16215

(a) This is an Open Access article distributed under the terms of the Creative Commons Attribution Non-Commercial License (http://creativecommons.org/licenses/by-nc/4.0) which permits unrestricted non-commercial use, distribution, and reproduction in any medium, provided the original work is properly cited. 
of transcriptional corepressors to the cccDNA. IFN- $\alpha$ mediates epigenetic repression of HBV cccDNA transcriptional activity. ${ }^{5}$ Therefore, HBsAg reduction is particularly prominent in patients receiving pegylated IFN (PegIFN) therapy. Furthermore, IFNs are crucial immunomodulators that interact with adaptive and innate immune responses. The major advantages of IFN-based therapy are a finite duration, absence of drug resistance, a high seroconversion rate, and an opportunity to obtain durable posttreatment responses; however, a modest antiviral effect, subcutaneous injections, and poor tolerability during treatment are the major obstacles for this therapy type.

\section{VALUE OF COMBINATION THERAPY}

Various studies have shown that HBV can potentially suppress innate immunity, including the Toll-like receptor signaling pathway, ${ }^{6,7}$ myeloid dendritic cell function, ${ }^{8}$ and IFN- $\alpha$ signaling by inhibiting nuclear translocation of signal transducer and activator of transcription $1 .{ }^{9}$ High levels of viral antigens (i.e., $\mathrm{HBeAg}$ and HBsAg) have been linked to T-cell exhaustion in patients with $\mathrm{CHB}{ }^{10,11}$

PegIFN- $\alpha$ and NUCs have differential effects on the innate and adaptive immune responses. PegIFN- $\alpha$ increases the production of IL-15 and expands natural killer (CD56 $6^{\text {bright }} \mathrm{NK}$ ) cells, with upregulation of tumor necrosis factor-related apoptosisinducing ligand (TRAIL) and IFN- $\gamma$ production; however, PegIFN- $\alpha$ depletes $\mathrm{CD}^{+} \mathrm{T}$ cells. ${ }^{12}$ Moreover, after long-term NUC therapy, HBV-specific CD8 ${ }^{+} \mathrm{T}$-cell functions can be restored. ${ }^{13}$ Potent NUC therapy can reduce TRAIL-expressing CD$56^{\text {bright }}$ NK cells, with defective capacity to produce the antiviral cytokine IFN- $\gamma$ (Table 1). ${ }^{14}$ The potential for PegIFN and NUC therapy to restore the impaired innate and adaptive immunity,

Table 1. The Effects of Pegylated Interferon and Nucleos(t)ide Analogues on Innate and Adaptive Immunity and Virological Control

\begin{tabular}{|c|c|c|}
\hline Clinical effect & PegIFN & NUC \\
\hline Innate immunity & $\begin{array}{l}\text { Increase the production of IL-15 and expands NK cells } \\
\text { (CD56 } 6^{\text {bright }} \mathrm{NK} \text { ), with upregulation of TRAIL and IFN- } \gamma \\
\text { production }\end{array}$ & $\begin{array}{l}\text { Reduce TRAIL-expressing CD56 }{ }^{\text {bright }} \text { NK cells, } \\
\text { with defective capacity to produce IFN- } \gamma\end{array}$ \\
\hline Adaptive immunity & Deplete $\mathrm{CD}^{+} \mathrm{T}$ cells amount and function & $\begin{array}{l}\text { Restore HBV-specific CD8 }{ }^{+} \text {T-cell function } \\
\text { after long-term treatment }\end{array}$ \\
\hline Overall effect & Suppress HBV replication and cccDNA transcription & Suppress HBV replication \\
\hline HBV DNA reduction & ++ & +++ \\
\hline HBeAg/HBsAg seroconversion & ++ & + \\
\hline
\end{tabular}

PegIFN, pegylated interferon; NUC, nucleos(t)ide analogue; NK, natural killer; TRAIL, tumor necrosis factor-related apoptosis-inducing ligand; HBV, hepatitis B virus; cccDNA, covalently closed circular DNA; HBeAg, hepatitis B e antigen; HBsAg, hepatitis B surface antigen.

Dual therapy

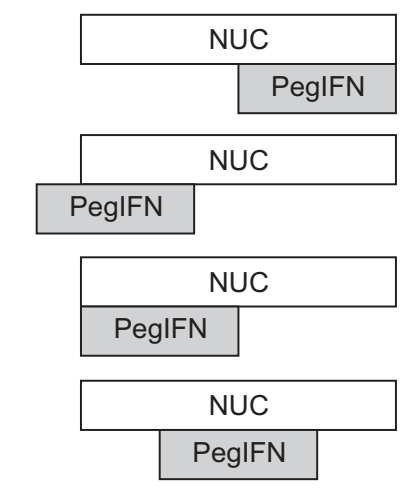

Switch therapy

NUC switches to PegIFN

\begin{tabular}{|l|l|}
\hline NUC & PegIFN \\
\begin{tabular}{|l|}
\hline NUC \\
\hline
\end{tabular} & PegIFN \\
\hline
\end{tabular}

PegIFN based therapy/add-on NUC

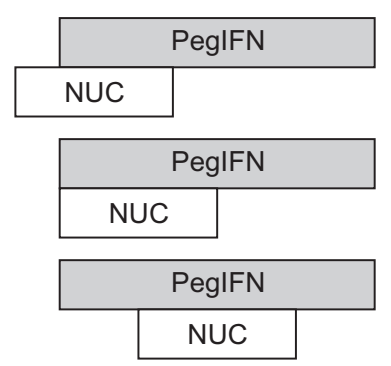

PegIFN switches to NUC

\begin{tabular}{l|l} 
PegIFN & NUC
\end{tabular}

Fig. 1. Diagram of combination therapy. Dual therapy is defined as the concurrent use of nucleos(t)ide analogues (NUCs) and interferon (IFN) during the entire treatment course. Add-on therapy is defined as a sequential combination of NUCs and pegylated IFN (PegIFN), whereby the combination is employed for more than 12 weeks, with two types of combinations: NUC-based therapy with add-on PegIFN and PegIFNbased therapy with add-on NUCs. Switch therapy is defined as a longterm NUC or PegIFN therapy with a subsequent switch to PegIFN or NUCs, with or without a short period ( $\leq 12$ weeks) of overlap of both agents. 
respectively, provides the rationale for combination therapy for CHB infection.

The main strength of immunomodulators is increasing the rate of seroconversion of HBeAg or HBsAg, whereas the advantage of NUCs is the rapid and sustained reduction of HBV DNA. Because monotherapy with IFN or NUCs is insufficient to eradicate CHB infection, a combination therapy is a potential strategy for eradicating this disease. ${ }^{15}$ Combination therapy has already been used in the treatment of human immunodeficiency virus and hepatitis $C$ virus infection. An efficient combination therapy should have additive or synergistic effects, prevent the development of drug resistance, and have low toxicity profiles. However, because of the limited information on the efficacy and safety of combining PegIFN with NUCs, the combination of PegIFN with lamivudine (LAM) or telbivudine (LdT) is not recommended by the 2012 EASL guideline (A1). ${ }^{2}$ In this paper, we provide current information on the role and efficacy of PegIFN-NUC combination therapy. According to the combination schedule, there are three types of combination therapy: "dual," "add-on," and "switch" therapies (Fig. 1).

\section{DUAL THERAPY}

The first studied combination strategy is dual therapy, which is defined as the concurrent use of NUCs and IFN throughout an entire treatment course (Fig. 1). The purpose of dual therapy is to increase the response rate of $\mathrm{HBeAg}$ seroconversion in IFN-resistant patients. ${ }^{16}$ Possible synergistic effects of the antiviral activity from both IFN and NUCs are expected, and these combinations are simple and generally well tolerated. In the observed data, nearly all NUCs were combined with IFN; furthermore, among all NUCs, the most abundant data were provided for LAM (Table 2).

\section{IFN and PegIFN plus lamivudine}

A randomized controlled trial (RCT) employed IFN- $\alpha 2 b$ (9 MU triweekly) plus LAM for 24 weeks and compared it with LAM monotherapy for 52 weeks in $151 \mathrm{HBeAg}$-positive patients. ${ }^{17}$ The combination therapy had a significantly higher rate of HBeAg seroconversion, with serum HBV DNA $<1.6 \mathrm{pg} / \mathrm{mL}$ (33\% vs $15 \%, p=0.014$ ), at 48 weeks after the end of therapy (EOT) and improvement of hepatic inflammation (46\% vs $27 \%, p=0.021$ ) at the EOT compared with LAM monotherapy. ${ }^{17}$ The combination therapy was also conducted for $50 \mathrm{HBeAg}$ negative patients, who were treated with IFN (5 MU triweekly) plus LAM or LAM monotherapy for 12 months. ${ }^{18}$ Because of a high relapse rate after therapy discontinuation, the response at 6 months after the EOT was similar between the two groups (17\% vs 19\%, p>0.05). The combination group developed fewer YMDD mutations during therapy. ${ }^{18}$

Subsequent studies have investigated the effect of combination therapy by using PegIFN, which exhibited increased ef- ficacy compared with conventional IFN. A multinational study included $814 \mathrm{HBeAg}$-positive $\mathrm{CHB}$ patients randomly assigned to receive PegIFN- $\alpha 2$ a plus either LAM or a placebo, or LAM monotherapy for 48 weeks. ${ }^{19}$ Patients who received PegIFN$\alpha 2 a-L A M$ or PegIFN- $\alpha 2 a$ monotherapy, compared with those who received LAM monotherapy, showed significantly greater HBeAg seroconversion (27\% vs 19\%, $\mathrm{p}=0.02$; 32\% vs $19 \%$, $\mathrm{p}<0.001$; respectively), with HBV DNA levels lower than $10^{5}$ copies/mL (34\% vs $22 \%, \mathrm{p}=0.003 ; 32 \%$ vs $22 \%$, $\mathrm{p}=0.01$; respectively) at 24 weeks after the EOT. Sixteen patients receiving PegIFN- $\alpha 2$ a, either alone or in combination, exhibited HBsAg seroconversion, compared with none in the LAM monotherapy group ( $\mathrm{p}=0.001){ }^{19}$ Another trial recruited $266 \mathrm{HBeAg}$-positive patients who were randomly assigned to receive PegIFN- $\alpha 2 b$ plus either LAM or a placebo for 52 weeks. ${ }^{20}$ More patients in the combination group cleared $\mathrm{HBeAg}$ at the EOT compared with those in the placebo group ( $44 \%$ vs $29 \%, \mathrm{p}=0.01$ ), but they relapsed during follow-up. The proportion of patients achieving HBeAg loss was similar in both groups at 26 weeks after the EOT (35\% vs 36\%, $p=0.91$ ). HBeAg loss rates were higher in patients with HBV genotypes A (47\%) and B (44\%) compared with those with genotypes C (28\%) and D (25\%). ${ }^{20}$

For HBeAg-negative patients, one multicenter trial included 537 patients randomly assigned to receive PegIFN- $\alpha 2$ a plus either LAM or a placebo, or LAM monotherapy for 48 weeks. ${ }^{21}$ After 24 weeks of follow-up, the percentage of patients with normalization of alanine aminotransferase (ALT) or HBV DNA levels $<20,000$ copies/mL was significantly higher for those receiving the PegIFN combination or monotherapy compared with those receiving LAM monotherapy (60\% vs $59 \%$ vs $44 \%$, $\mathrm{p}<0.01 ; 44 \%$ vs $43 \%$ vs $29 \%, \mathrm{p}<0.01$ ). Similarly, the addition of LAM did not improve response rates. ${ }^{21}$ A 3 -year posttreatment follow-up showed that PegIFN-based therapy, compared with LAM monotherapy, demonstrated a significantly higher rate of ALT normalization (31\% vs 18\%, $p=0.032$ ), with HBV DNA levels $\leq 10,000$ copies $/ \mathrm{mL}$ ( $28 \%$ vs $15 \%, \mathrm{p}=0.039$ ). Of the patients who received PegIFN, 8.7\% cleared HBsAg. ${ }^{22}$

\section{PegIFN plus adefovir}

Adefovir (ADV) monotherapy has been shown to reduce cccDNA (0.8 log copies/cell) and intracellular total HBV DNA (1.6 log copies/cell) through a noncytolytic mechanism, possibly the suppression of the cytoplasmic nucleocapsid pool to replenish nuclear cccDNA. ${ }^{23}$ Combination therapy with PegIFN- $\alpha 2 b$ and ADV for 48 weeks in a pilot study $(n=26)$ led to marked decreases in serum HBV DNA, as well as intrahepatic total HBV DNA, and cccDNA ( -2.2 and $-2.4 \log _{10}$ reductions, respectively), which were significantly correlated with reduced HBsAg. ${ }^{24}$

A multicenter RCT recruited $60 \mathrm{HBeAg-negative} \mathrm{patients}$ receiving either PegIFN- $\alpha 2 a$ plus ADV or PegIFN- $\alpha 2 a$ monotherapy for 48 weeks. Although there was a greater ontreatment efficacy for the combination group, the sustained 


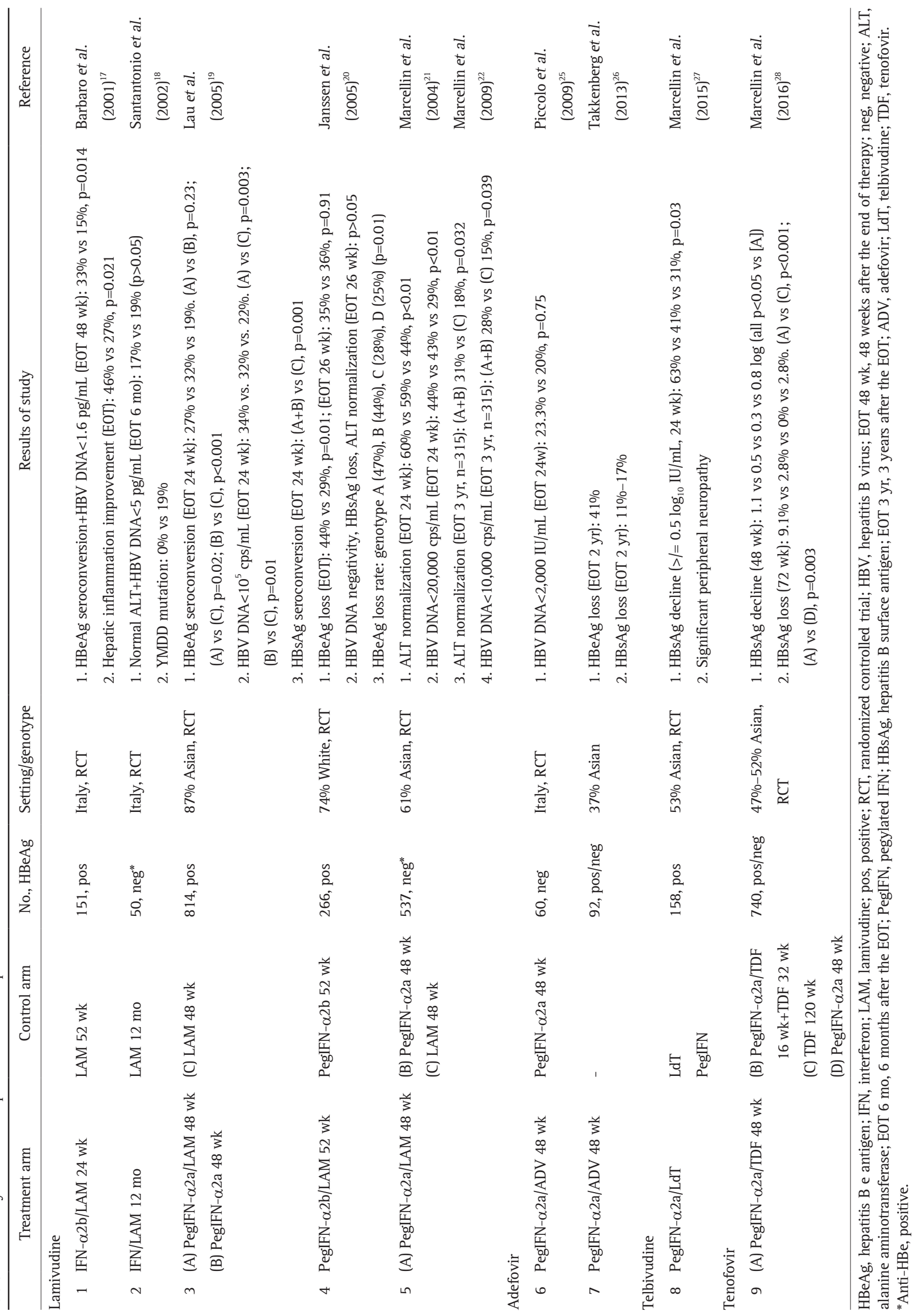


virological response (SVR) defined as HBV DNA <2,000 IU/mL was similar (23.3\% vs $20 \%, \mathrm{p}=0.75$ ) at week $72 .{ }^{25}$ A single-arm study recruited $92 \mathrm{CHB}$ patients receiving PegIFN plus ADV for 48 weeks with a follow-up of 2 years. The rates of HBeAg loss and HBsAg loss (2 years after the EOT) in the HBeAg-positive patients were $41 \%(18 / 44)$ and $11 \%(5 / 44)$, respectively. In the $\mathrm{HBeAg}$-negative patients, the rates of combined response (HBV DNA $\leq 2,000 \mathrm{IU} / \mathrm{mL}$ and ALT normalization) and HBsAg loss were $25 \%(12 / 48)$ and $17 \%(8 / 48)$, respectively. ${ }^{26}$

\section{PegIFN plus telbivudine}

The combination therapy of PegIFN- $\alpha 2$ a plus LdT was evaluated in an RCT enrolling HBeAg-positive CHB patients. A rapid decline of HBsAg ( $\geq 0.5 \log _{10} \mathrm{IU} / \mathrm{mL}$ ) was observed in the combination group, compared with the LdT and PegIFN monotherapy groups ( $63 \%$ vs $41 \%$ vs $31 \%, p=0.03$ ). However, the study was terminated prematurely because of a high rate of peripheral neuropathy in the combination group compared with the LdT and PegIFN- $\alpha 2 a$ monotherapy groups. Therefore, the combination of PegIFN plus LdT should not be used, despite the rapid and profound reduction in HBV DNA levels compared with those of the two monotherapy groups. ${ }^{27}$

\section{PegIFN plus tenofovir}

A major challenge in previous dual therapies was the emergence of NUC resistance over time, especially in therapies using drugs with a relatively low genetic barrier to resistance. Tenofovir (TDF) is a potent NUC without documented resistance in naïve patients. In an open-label, active-controlled study, $740 \mathrm{CHB}$ patients were randomly assigned to receive TDF plus PegIFN- $\alpha 2 a$ for 48 weeks (group A), TDF plus PegIFN- $\alpha 2 a$ for 16 weeks followed by TDF for 32 weeks (group B), TDF for 120 weeks (group C), or PegIFN- $\alpha 2 a$ for 48 weeks (group D). ${ }^{28}$ Mean $\mathrm{HBsAg}$ reduction from the baseline to week 48 was significantly greater in group $\mathrm{A}\left(1.1 \log _{10} \mathrm{IU} / \mathrm{mL}\right)$ than in groups $\mathrm{B}, \mathrm{C}$, and $\mathrm{D}$ $\left(0.5,0.3\right.$, and $0.8 \log _{10} \mathrm{IU} / \mathrm{mL}$, respectively; $\mathrm{p}<0.05$ for all groups vs group A). At week 72, the HBsAg loss rates were 9.1\%, 2.8\%, $0 \%$, and $2.8 \%$ in groups $\mathrm{A}, \mathrm{B}, \mathrm{C}$, and $\mathrm{D}$, respectively (group A vs group $C, p<0.001$; group A vs group $D, p=0.003$ ). Group $A$ and genotype A were two baseline predictors associated with $\mathrm{HBsAg}$ loss. $^{28}$

\section{Summary of dual therapy studies}

The findings of the aforementioned heterogeneous studies should be carefully interpreted concerning the various study designs, inclusion of control groups, definition of treatment outcome, timing of outcome measurement, detection limit of $\mathrm{HBV}$ DNA in earlier studies, and HBV genotypes and HBeAg status of enrolled patients. According to these studies, compared with LAM monotherapy, dual therapy has a significantly higher $\mathrm{HBeAg}$ loss or seroconversion rate in $\mathrm{HBeAg}$-positive patients. The inferiority of NUC monotherapy may be because of its in- adequate treatment duration (i.e., only 1 year) as well as withdrawal hepatitis without a consolidation period.

Compared with PegIFN monotherapy, dual therapy with LAM can improve the on-treatment viral suppression; however, there is no additional benefit in SVR after treatment cessation, or in the HBeAg loss or seroconversion rate. Combination with a NUC (e.g., ADV) appears to more effectively reduce cccDNA or intrahepatic HBV DNA compared with monotherapy. This is further verified by data regarding the dual therapy PegIFN-TDF. Given an endpoint of HBsAg reduction, PegIFN-TDF has significantly greater efficacy compared with TDF or PegIFN monotherapy.

\section{ADD-ON THERAPY}

The second studied combination strategy is add-on therapy, which is a sequential combination of NUCs and PegIFN, with a lead-in phase of either NUCs or PegIFN. The period during which the agents are combined is defined as greater than 12 weeks. We reviewed two types of sequential combinations: NUC-based therapy with add-on PegIFN, and PegIFN-based therapy with add-on NUCs. Because low HBV DNA levels are associated with a favorable response to IFN, one objective of add-on therapy starting with NUCs is to lower the viral load before IFN therapy is initiated, thereby restoring treatment sensitivity to IFN. Another objective of sequential therapy is to prevent the relapse of hepatitis following the discontinuation of NUC therapy through the use of IFN. ${ }^{29}$ NUC add-on therapy may increase the viral control in PegIFN-poor virological responders (Table 3).

\section{NUC-based therapy plus add-on PegIFN}

The first reviewed add-on therapy trial enrolled 230 treatment-naïve HBeAg-positive patients receiving LAM treatment for 8 weeks, followed by LAM plus IFN- $\alpha 2 b$ (10 MU triweekly) for 16 weeks; IFN- $\alpha 2 b$ monotherapy for 16 weeks; or LAM monotherapy for 52 weeks. The HBeAg seroconversion rate at week 52 was similar among the three groups (29\%, 19\%, and $18 \%$, respectively, all $\mathrm{p}>0.05) .^{30}$ Several smaller studies investigating LAM therapy with add-on IFN have been conducted with inconsistent results. ${ }^{29}$ One RCT enrolled $100 \mathrm{HBeAg}$-positive Chinese patients who received either PegIFN- $\alpha 2 b$ (weeks 1 to 32) and LAM (weeks 9 to 60), or LAM monotherapy for 52 weeks. ${ }^{31}$ Patients receiving the combination therapy exhibited a greater reduction of HBV DNA and fewer LAM-resistant mutants at the EOT compared with the LAM monotherapy group (21\% vs $40 \%$ ). The SVR rate (HBeAg seroconversion and HBV DNA $<500,000$ copies $/ \mathrm{mL}$ ) at 24 weeks after the EOT was significantly higher for the combination treatment group (36\% vs $14 \%, p=0.011) .^{31}$ A follow-up report showed that the combination group had a higher SVR than did the LAM monotherapy group for up to 3 years after treatment (29\% vs 9\%, log-rank test, $\mathrm{p}=0.0015)^{32}$ 


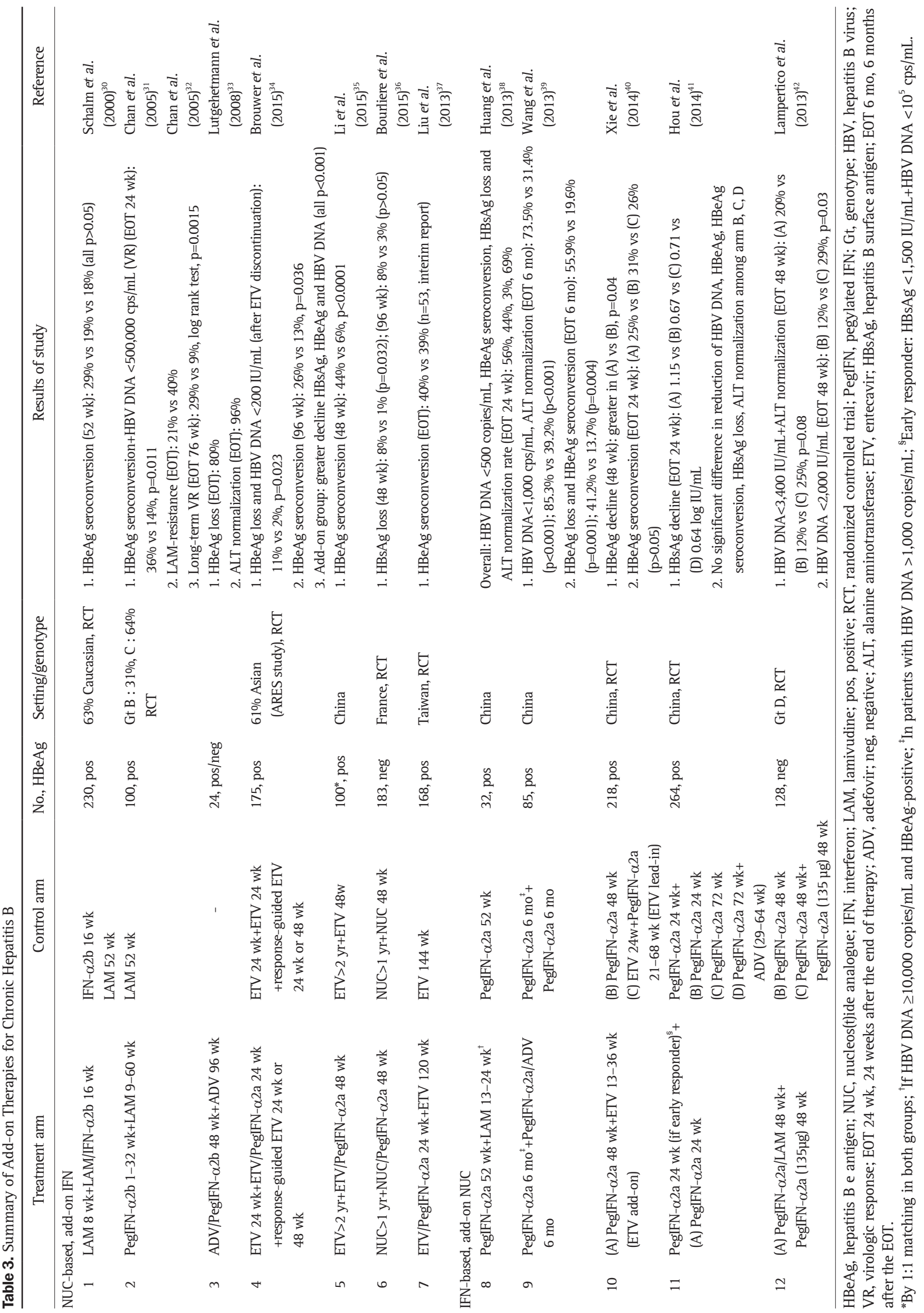


In an extension study of $26 \mathrm{CHB}$ patients receiving a PegIFN$\alpha 2 b-A D V$ combination for 48 weeks, ${ }^{24} 24$ patients continued treatment with 96 weeks of ADV monotherapy. At week 144, 80\% (12/15) of HBeAg-positive patients lost HBeAg, and ALT levels normalized in 23 patients (96\%). The reduction of intrahepatic HBV DNA was maintained in the patients receiving the additional 96 weeks of ADV monotherapy. ${ }^{33}$

The ARES study was a multicenter, randomized, open-label study; 175 HBeAg-positive patients received entecavir (ETV) lead-in therapy for 24 weeks and were subsequently randomized to either receive PegIFN- $\alpha 2$ a plus ETV for 24 weeks $(n=85)$ or continue ETV for 24 weeks $(n=90){ }^{34}$ For both arms, responders at week 48 (HBeAg loss with $\mathrm{HBV}$ DNA $<200 \mathrm{IU} / \mathrm{mL}$ ) received ETV consolidation therapy for 24 weeks, whereas nonresponders continued ETV monotherapy for an additional 48 weeks (through week 96). There was a nonsignificant increase in the response rate of the add-on group compared with that of the monotherapy group at week 48 (19\% vs 10\%, p=0.095); the difference between the responses became significant after discontinuation of ETV ( $11 \%$ vs $2 \%, p=0.023$ ). The HBeAg seroconversion rate was greater in the add-on group (26\% vs $13 \%, \mathrm{p}=0.036$ ) at week 96. The add-on therapy resulted in a greater decline in HBsAg, HBeAg, and HBV DNA, and appeared to prevent relapse after discontinuation of ETV at week $96 .^{34}$

A retrospective study included 100 match-paired HBeAgpositive patients undergoing ETV therapy for more than 2 years without HBeAg seroconversion who received add-on PegIFN$\alpha 2 \mathrm{a}$ or continued ETV monotherapy for 48 weeks. The HBeAg seroconversion rate at week 48 was significantly increased in the add-on group ( $44 \%$ vs $6 \%, \mathrm{p}<0.0001) .{ }^{35}$ There were no offtherapy responses available.

Another multicenter RCT enrolled 183 HBeAg-negative patients who had had an undetectable HBV DNA load for greater than 1 year. ${ }^{36}$ The patients were randomly assigned to receive either NUC therapy plus add-on PegIFN- $\alpha 2$ a or NUC monotherapy for 48 weeks. At week 48, HBsAg clearance was observed in seven patients (8\%) in the add-on group and one patient in the NUC group ( $p=0.032)$; however, this difference was nonsignificant at week 96. Adherence to this combination regimen was poor, and treatment was discontinued owing to adverse events occurring in $20 \%$ of the patients. ${ }^{36}$

One multicenter RCT in Taiwan enrolled $168 \mathrm{HBeAg}$-positive patients who received PegIFN- $\alpha 2 a$ plus ETV for 24 weeks followed by ETV alone for 120 weeks, or ETV monotherapy for 144 weeks. The interim report showed that $40 \%(n=25)$ of patients in the combination group and $39 \%(n=28)$ in the ETV monotherapy group achieved $\mathrm{HBeAg}$ seroconversion at week $144 .^{37}$ The final results are pending.

\section{PegIFN-based therapy plus add-on NUCs}

A response-guided add-on therapy was evaluated in a study of $32 \mathrm{HBeAg}$-positive CHB patients receiving PegIFN- $\alpha 2 \mathrm{a}$ at
$135 \mu \mathrm{g} /$ week for 52 weeks. If HBV DNA was $\geq 10,000$ copies/ $\mathrm{mL}$ and $\mathrm{HBeAg}$ was still positive at 12 weeks of treatment, LAM was added on for 12 weeks (weeks 13 to 24). For this responseguided strategy, the sustained HBV DNA loss ( $<500$ copies $/ \mathrm{mL})$, HBeAg seroconversion, HBsAg loss, and ALT normalization rates (24 weeks after the EOT) were 56\% (18/32), 44\% (14/32), 3\% (1/32), and 69\% (22/32), respectively. ${ }^{38}$

The NUC add-on therapy improved the response rate in PegIFN-poor virological responders. A total of $85 \mathrm{HBeAg}$-positive patients who had HBV DNA >1,000 copies/mL after receiving PegIFN- $\alpha 2 \mathrm{a}$ at $180 \mu \mathrm{g} /$ week for 6 months chose to continue PegIFN ( $n=51)$ or begin add-on ADV $(n=34)$ for another 6 months of therapy; respectively, at 6 months after the EOT, the rates of HBV DNA $<1,000$ copies/mL were 31.4\% and 73.5\% ( $<<0.001)$, the ALT normalization rates were 39.2\% and 85.3\% ( $<<0.001)$, the $\mathrm{HBeAg}$ loss rates were $19.6 \%$ and $55.9 \%$ ( $\mathrm{p}=0.001$ ), and the $\mathrm{HBeAg}$ seroconversion rates were $13.7 \%$, and $41.2 \%(\mathrm{p}=0.004){ }^{39}$

In another RCT, a total of 218 treatment-naïve HBeAgpositive patients received PegIFN- $\alpha 2$ a for 48 weeks; they were divided into three groups: PegIFN monotherapy; ETV add-on, receiving ETV for 24 weeks during weeks 13 to 36; and ETV pretreatment, receiving ETV for 24 weeks, starting 21 weeks before PegIFN treatment. ${ }^{40}$ The add-on group showed a significant on-treatment HBeAg decline compared with the PegIFN monotherapy group at week $48(\mathrm{p}=0.04)$; however, the rates of $\mathrm{HBeAg}$ seroconversion at 24 weeks after the EOT were similar among the treatment groups ( $31 \%$ vs $25 \%$ vs $26 \%$, all p>0.05). ${ }^{40}$

In another trial, $264 \mathrm{HBeAg}$-positive $\mathrm{CHB}$ patients were enrolled in a response-guided therapy. After 24 weeks of PegIFN$\alpha 2 \mathrm{a}$ therapy, early responders (HBsAg $<1,500 \mathrm{IU} / \mathrm{mL}$ and $\mathrm{HBV}$ DNA $<10^{5}$ copies $/ \mathrm{mL}$ ) were administered PegIFN- $\alpha 2$ a treatment for 24 weeks (group A); other patients were randomized into groups receiving PegIFN- $\alpha 2 a$ for 24 weeks (group B), PegIFN$\alpha 2$ a for 72 weeks (group C), or PegIFN- $\alpha 2$ a for 72 weeks plus add-on ADV (at weeks 29 to 64) (group D). ${ }^{41}$ A greater HBsAg decline was noted in group $\mathrm{A}$, compared with the other groups (1.15 log, $0.67 \log , 0.71 \mathrm{log}$, and $0.64 \log$ in groups A, B, C, and D, respectively). No significant difference in response rates for any other efficacy endpoints (i.e., HBsAg loss, ALT normalization, or reduction of HBV DNA, HBeAg, or HBeAg seroconversion) were observed among groups $\mathrm{B}, \mathrm{C}$, and $\mathrm{D}^{41}$

For HBeAg-negative patients, the extension of PegIFN therapy to 96 weeks was evaluated. In an RCT, $128 \mathrm{HBeAg-}$ negative genotype $\mathrm{D}$ CHB patients were randomly assigned to receive PegIFN- $\alpha 2$ a for 48 weeks, PegIFN- $\alpha 2$ a for 48 weeks followed by PegIFN- $\alpha 2 a$ (135 $\mu \mathrm{g}$ weekly) for another 48 weeks, or PegIFN- $\alpha 2$ a plus LAM for 48 weeks followed by PegIFN- $\alpha 2 a$ (135 $\mu \mathrm{g}$ weekly) for 48 weeks; ${ }^{42}$ the rates of primary endpoint achievement (HBV DNA <3,400 IU/mL and ALT normalization) at 48 weeks after the EOT were 12\%, 25\%, and 20\% ( $p=0.08)$. Extended treatment with PegIFN- $\alpha 2$ a for 96 weeks compared with 48 weeks resulted in a higher percentage of patients with 
HBV DNA <2,000 IU/mL (29\% vs 12\%, p=0.03), but the rates of ALT normalization were similar. The combination with LAM did not improve the response rate. ${ }^{42}$

\section{Summary of add-on therapy studies}

As in the dual therapy studies, the problems with the add-on therapy studies were the heterogeneous patient populations and therapeutic regimens, causing difficulty in demonstrating the benefit of add-on therapy. Compared with 1-year NUC monotherapy, add-on PegIFN leads to higher rates of virologic response during treatment and SVR after treatment. The off-therapy response of add-on PegIFN regarding HBsAg, $\mathrm{HBeAg}$, and HBV DNA decline remains evident; therefore, PegIFN add-on therapy may facilitate the discontinuation of NUCs. The efficacy of add-on PegIFN concerning HBsAg loss is associated with low baseline HBsAg and the overall dosage of and compliance with PegIFN. ${ }^{36}$ However, if long-term (3-year) potent NUC therapy is used for comparison, it appears that add-on PegIFN provides no additional benefit. ${ }^{37}$ According to the Japanese Study Group of the Standardization of Treatment of Viral Hepatitis, in patients with HBV DNA $\geq 7$ log copies/mL who are aged $<35$ years, sequential treatment with ETV followed by IFN is recommended as the first-line therapy for those who are HBeAg negative and as the second-line therapy for those who are HBeAg positive. ${ }^{43}$

However, add-on NUCs in PegIFN-based therapy seem to provide no additional benefit compared with PegIFN monotherapy, regardless of the NUC add-on or lead-in regimen. Furthermore, the addition of $\mathrm{ADV}$, which may reduce cccDNAs, appears to have no benefit. Moreover, in HBeAg-positive patients without an early response to PegIFN- $\alpha 2 \mathrm{a}$, a 48-week extension therapy with PegIFN has no additional efficacy, regardless of the addition of ADV. Only in HBeAg-negative genotype D patients, extended treatment with PegIFN to 96 weeks safely improves SVR compared with the current 48-week standard of care.

Previous studies have not shown the beneficial effects of addon therapy, likely because of the usage of insufficiently potent agents, the short duration of NUC combinations (up to 1 year), and immediate stopping of both antiviral agents after 1 year of treatment. ${ }^{44}$ NUC therapy typically requires several months to achieve complete suppression of viral replication. Because it takes time for $\mathrm{T}$ cells to restore their CD8+ function after NUC therapy, incorporating a late add-on therapy with PegIFN- $\alpha$ into an ongoing NUC therapy might be beneficial. The added PegIFN may accelerate the decline of circulating and intrahepatic viral antigens and promote the expansion of antiviral NK cells. ${ }^{13}$ This concept has been explored in switch therapy.

\section{SWITCH THERAPY}

The third studied combination strategy is switch therapy: after a long-term NUC therapy with suboptimal response, the NUC therapy is switched to PegIFN therapy, with or without a short period ( $\leq 12$ weeks) of overlap of both agents; alternatively, PegIFN therapy can be switched to NUC therapy. This approach is effective because a high HBV DNA load is associated with an inefficient $\mathrm{T}$ cell response to $\mathrm{HBV}$-related antigens such as $\mathrm{HB}-$ sAg. Long-term treatment with NUC therapy recovers the T cell immune response and increases the efficacy of immunomodulator therapy. ${ }^{45}$ In addition, low HBV DNA levels or HBeAg titers after long-term NUC therapy are efficient predictors for subsequent IFN therapy.

Switching to NUCs from PegIFN therapy is beneficial regarding reduced treatment-related adverse events and treatment costs because of the shortened duration of PegIFN therapy (Table 4).

\section{Switching from NUCs to PegIFN therapy}

The first study on switch therapy was conducted by Sarin et al. ${ }^{46}$ In this study, $66 \mathrm{HBeAg}$-positive patients were assigned to receive LAM or a placebo for 4 weeks, followed by PegIFN at 1.0 $\mu \mathrm{g} / \mathrm{kg} /$ wk for 24 weeks; respectively, at 24 weeks after the EOT, the HBeAg loss rates were $38.9 \%$ and $14.8 \%(p=0.05)$, whereas the HBV DNA undetectability rates were $50 \%$ and $14.8 \%$ $(p=0.028)$. This pilot study indicated that a lead-in NUC therapy for reducing the HBV DNA level before immunomodulator therapy increases the SVR. ${ }^{46}$

The NEED study was a randomized, placebo-controlled, double-blind study on PegIFN- $\alpha 2$ a plus ADV or ETV in HBeAgpositive $\mathrm{CHB}$ patients. The patients were randomized into groups receiving $\mathrm{ADV}$, ETV, or a placebo in a 1:1:1 ratio (weeks 1 to 6), followed by PegIFN- $\alpha 2$ a (weeks 5 to 52); the interim report showed similar HBeAg seroconversion at 24 weeks after the EOT (23\%, 28\%, and 36\%, respectively, all pairwise $p>0.05) .{ }^{47}$ The final report is still pending.

In the OSST trial, $192 \mathrm{HBeAg}$-positive patients receiving 9 to 36 months of ETV therapy without $\mathrm{HBeAg}$ seroconversion (HBeAg $<100 \mathrm{PEIU} / \mathrm{mL}$ and HBV DNA $\leq 1,000$ copies $/ \mathrm{mL}$ ) were randomized in a $1: 1$ ratio ( $51 \%$ to $55 \% \mathrm{HBeAg}$ negative) to receive ETV monotherapy for 48 weeks or switch to PegIFN$\alpha 2 \mathrm{a} 48$ weeks with an ETV overlap of 8 weeks. ${ }^{48}$ A significantly higher number of patients receiving PegIFN- $\alpha 2 a$ therapy, compared with those receiving ETV monotherapy, achieved HBeAg seroconversion ( $14.9 \%$ vs $6.1 \%, p=0.0467)$ or HBsAg loss $(8.5 \%$ vs $0 \%, p=0.0028$ ), as determined by a modified intention-totreat analysis at the EOT. The crucial finding of this study is that patients who lose HBeAg and have HBsAg levels $<1,500 \mathrm{IU} / \mathrm{mL}$ with ETV may consider switching from ETV to PegIFN therapy because of its reasonable efficacy in HBsAg loss (22.2\%) and HBeAg seroconversion (33.3\%). ${ }^{48}$

The NEW SWITCH study involved HBeAg-positive CHB patients who achieved HBV DNA <200 IU/mL and HBeAg loss through NUC therapy for 1 to 3 years. All participants were switched to PegIFN- $\alpha 2$ a treatment (1:1) for 48 or 96 weeks (with NUC overlap for the first 12 weeks). A total of 17.3\% of the patients (47/271) who completed 48 weeks of therapy achieved 


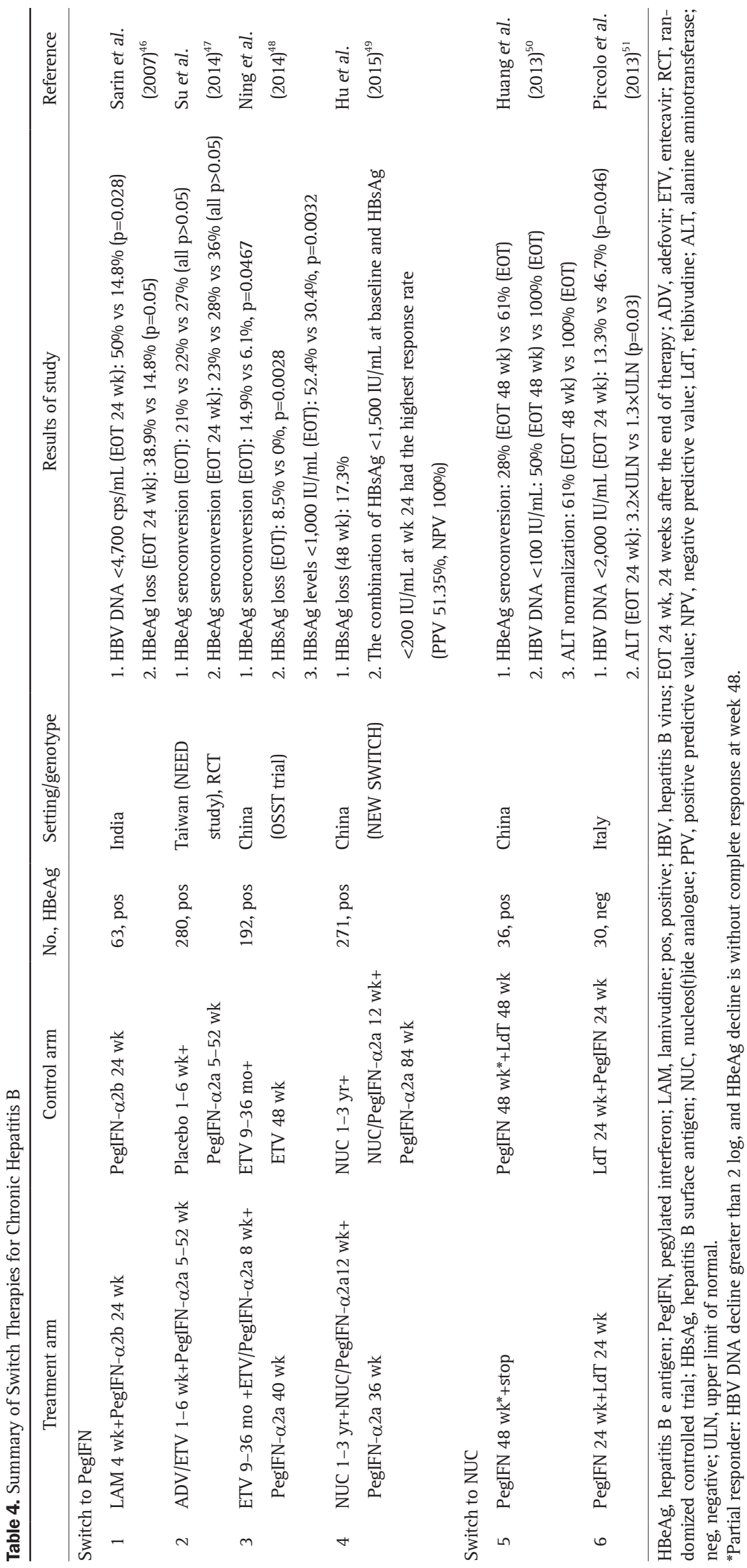


HBsAg loss at week 48. Patients with baseline HBsAg $<1,500$ $\mathrm{IU} / \mathrm{mL}$ (vs $\geq 1,500 \mathrm{IU} / \mathrm{mL}$ ) and on-treatment HBsAg levels $<200$ $\mathrm{IU} / \mathrm{mL}$ (vs $\geq 200 \mathrm{IU} / \mathrm{mL}$ ) at week 24 achieved a higher $\mathrm{HBsAg}$ loss rate $(33.3 \%$ vs $4.1 \%, \mathrm{p}<0.0001 ; 48.4 \%$ vs $0.6 \%$, $\mathrm{p}<0.0001$; respectively). ${ }^{49}$

\section{Switching from PegIFN to NUC therapy}

It is unknown whether reducing viral load with NUCs before PegIFN therapy is more effective than starting NUCs after PegIFN treatment. Two previous studies have investigated switch therapy from PegIFN to NUCs. A small-scale study conducted in China enrolled 36 HBeAg-positive patients undergoing PegIFN therapy with partial response (i.e., HBV DNA decline greater than $2 \log$ and HBeAg decline without complete response at week 48). The patients were divided into two groups receiving either PegIFN monotherapy (group A) or PegIFN switching to LdT (group B) for 48 weeks. ${ }^{50}$ Group B exhibited numerically higher rates of $\mathrm{HBeAg}$ seroconversion, HBV DNA $<100 \mathrm{IU} / \mathrm{mL}$, and ALT normalization at week 96 (end of LdT therapy) compared with group A (48 weeks after the end of PegIFN therapy). However, there were no off-therapy results from group B and the study was not randomized. Another small-scale study included $30 \mathrm{HBeAg}$-negative patients randomized in a $1: 1$ ratio into groups receiving PegIFN- $\alpha 2$ a for 24 weeks followed by LdT for 24 weeks (i.e., PegIFN first) or vice versa (i.e., LdT first); respectively, the rates of $\mathrm{HBV}$ DNA $<2,000 \mathrm{IU} / \mathrm{mL}$ at 24 weeks after the EOT were 13.3\% and 46.7\% ( $\mathrm{p}=0.046)$. The ALT level at 24 weeks after the EOT was significantly lower in the LdT-first group (1.3xupper limit of normal [ULN] vs $3.2 \times U L N, p=0.03$ ). ${ }^{51}$ Patients who received PegIFN followed by LdT showed a greater rebound of HBV DNA after LdT suspension. ${ }^{51}$

\section{Summary of switch therapy studies}

Switch therapy involving a switch to a NUCs achieves greater virological suppression compared with continual NUC monotherapy. However, the problem of the switch studies is that the off-therapy findings have not been reported, and patients were highly selected; additional studies regarding switch therapy are required. Another crucial issue regarding the switch from Peg IFN to NUCs is the rebound of HBV DNA after the discontinuation of the NUCs. Therefore, PegIFN should be used before the cessation of combination therapy to prevent off-therapy relapse.

Combination therapy provides potential to cure $\mathrm{CHB}$, primarily because of the addition of PegIFN for its immunomodulatory effects. Several strategies have been proposed for improving the therapeutic outcomes of combination therapies. For example, pretreatment or on-treatment biomarkers may predict the responses to IFN-based therapy. Response-guided therapy according to short-term or mid-term endpoints also increases the chances of an optimal therapeutic outcome and reduces the adverse reactions to PegIFN therapy. The findings for these strategies indicate that physicians should adopt individualized plans for their patients to increase the chance of cure.

\section{VIRAL PREDICTORS OF COMBINATION THERAPY}

HBV serological markers have shown clinical implications in the management of $\mathrm{CHB}$, including $\mathrm{HBs} A g$, $\mathrm{HBeAg}$, anti$\mathrm{HBc}$, and hepatitis B core-related antigen (HBcrAg). The HBsAg level may reflect the transcription activity of HBV cccDNA. The quantitative $\mathrm{HBsAg}$ level pedicts disease activity, HBsAg loss, and development of HCC in the natural history, ${ }^{52-57}$ as well as the responses to treatment. ${ }^{58-60}$ Several cross-sectional studies have revealed a dynamic change of HBsAg levels during the natural course of HBV infection. ${ }^{61-64}$ Another study showed that among HBeAg-negative carriers, an on-treatment HBsAg decline greater than $0.5 \log$ at week 12, or an on-treatment HBsAg decline greater than $1 \mathrm{log}$ at week 24 can predict SVR. ${ }^{60}$ If these $\mathrm{HBeAg}$-negative patients received 48 weeks of PegIFN therapy, an EOT HBsAg reduction greater than $1 \log$ or $\mathrm{HBsAg}<10 \mathrm{IU} /$ $\mathrm{mL}$ was highly associated with $\mathrm{HBsAg}$ seroclearance 3 years posttreatment. $^{58}$

Quantitative HBeAg testing has been used less frequently because of the lack of commercially available assays. Fried et al. ${ }^{65}$ demonstrated a moderately significant relationship between baseline HBeAg levels and subsequent HBeAg seroconversion in patients receiving PegIFN. A baseline HBeAg level of $\leq 31 \mathrm{PE}$ $\mathrm{IU} / \mathrm{mL}$ was associated with a $>50 \%$ chance of $\mathrm{HBeAg}$ seroconversion. The on-treatment $\mathrm{HBeAg}$ levels were also negatively predictive of HBeAg seroconversion; if the HBeAg level was still >100 PE IU/mL at weeks 12 and 24, only 14\% and 4\% of patients achieved HBeAg seroconversion at week 72, respectively. ${ }^{65}$ In a recent study on $65 \mathrm{HBeAg}$-positive $\mathrm{CHB}$ patients receiving ETV, quantification of $\mathrm{HBeAg}$ at the baseline and 24 weeks during therapy showed a higher predictive value than that of HBV DNA for HBeAg seroconversion. A >65\% decrease in serum HBeAg levels at week 24 may be a useful early ontreatment marker for predicting $\mathrm{HBeAg}$ seroconversion. ${ }^{66}$

These data suggest the potential role of quantitative HBsAg and HBeAg levels in prediction of the therapeutic response to combination therapy. In a study investigating the combination therapy of PegIFN plus LAM, a pretreatment HBsAg level $<10,000 \mathrm{IU} / \mathrm{mL}$ or an EOT HBsAg level $<1,500 \mathrm{IU} / \mathrm{mL}$ predicted HBV DNA $<10,000$ copies/mL at 1 year after treatment. ${ }^{67}$ The combination of baseline $\mathrm{HBeAg}<200$ signal to cutoff, HB$\mathrm{sAg}<1,000 \mathrm{IU} / \mathrm{mL}$, and an HBsAg decline at week 12 of $>0.5$ $\log _{10} \mathrm{IU} / \mathrm{mL}$ predicts the highest rate of HBeAg seroconversion (92.31\%) and HBsAg loss (83.3\%) at week 48 of PegIFN-ETV therapy. ${ }^{35}$ A recent study suggested that patients with baseline HBsAg $<1,500 \mathrm{IU} / \mathrm{mL}$ and $\mathrm{HBsAg}<200 \mathrm{IU} / \mathrm{mL}$ at week 24 had the highest response rate to PegIFN switch therapy from NUCs (positive predictive value, 51.35\%; negative predictive value, $100 \%)$. Therefore, the combination of baseline and 24-week HBsAg levels may predict HBsAg loss at week 48 in HBeAg-posi- 
tive CHB patients who switched to PegIFN- $\alpha 2$ a after achieving partial responses in NUC treatment. ${ }^{49}$

In a recent study, a quantitative anti-HBc antibody indicated host immunity against the hepatitis B core protein. ${ }^{68} \mathrm{HBcrAg}$, consisting of HBV core antigen, $\mathrm{HBeAg}$, and the $22-\mathrm{kDa}$ precore protein (p22cr), was suggested as an additional marker of $\mathrm{CHB}^{69}$ The role of this antigen in the prediction of combination therapy should be further explored.

Combination therapy may represent a potential cure for CHB. Currently, the combination of PegIFN and TDF and switch therapy from NUCs to PegIFN appear to be the most promising forms of therapy in this regard. A debate remains concerning the superiority of the add-on or switch strategy. Moreover, the reduction of $\mathrm{HBV}$ replication by potent NUCs prolongs the early immunological response to PegIFN therapy. ${ }^{70}$ Combination therapy might prevent the replenishment of nuclear cccDNA after PegIFN-induced degradation. ${ }^{71}$ The optimal timing, duration, and indications of combination therapy remain to be explored in larger clinical trials.

In addition to NUCs and PegIFN, new agents for combination have been investigated. The combination of IFN and ribavirin was evaluated in an RCT examining HBeAg-positive patients. However, adding ribavirin did not increase the efficacy of IFN. ${ }^{72}$ New therapeutic agents targeting cccDNA or immunotherapy for $\mathrm{CHB}$ are under active investigation. ${ }^{73}$ For example, Myrcludex targets HBV entry receptors and inhibits the amplification of intrahepatic cccDNA as well as intrahepatic viral spread. Myrcludex may be combined with current HBV drugs to improve patient treatment outcomes. ${ }^{74}$

An optimal combination therapy course should employ longterm potent NUC therapy to suppress viral replication and regain the HBV-specific T cell activity, followed by a sequential late add-on of or switch to immunomodulatory PegIFN treatment. This strategy can preferably be applied in patients with low quantitative $\mathrm{HBsAg}$ and $\mathrm{HBeAg}$ titers after long-term NUC therapy, indicating a robust immune control similar to the late stage of the immune clearance phase. High compliance with PegIFN is crucial to therapy success, and whether a lower dose of PegIFN can be used for prolonged therapy awaits further evaluation.

\section{CONCLUSIONS}

Combination therapy with NUCs and PegIFN increases the chance of curing $\mathrm{CHB}$ through their synergistic antiviral activity and immunomodulatory effects. Future studies must determine the optimal regimen and duration for add-on or switch combination therapy strategies. The optimal candidates for combination therapy can be identified using viral or host predictors to increase the rate of HBV eradication.

\section{CONFLICTS OF INTEREST}

No potential conflict of interest relevant to this article was reported.

\section{ACKNOWLEDGEMENTS}

The work was supported by grants from National Taiwan University, Taiwan Liver Disease Consortium, National Taiwan University Hospital (105-S2975), the Ministry of Science and Technology, Taiwan (NSC 102-2314-B-002-160-MY3), and National Health Research Institutes (NHRI-EX103-10319PC).

\section{REFERENCES}

1. $\mathrm{Su} \mathrm{TH}, \mathrm{Kao} \mathrm{JH}$. Improving clinical outcomes of chronic hepatitis B virus infection. Expert Rev Gastroenterol Hepatol 2015;9:141-154.

2. European Association for the Study of the Liver. EASL clinical practice guidelines: management of chronic hepatitis B virus infection. J Hepatol 2012;57:167-185

3. Wieland SF, Guidotti LG, Chisari FV. Intrahepatic induction of alpha/beta interferon eliminates viral RNA-containing capsids in hepatitis B virus transgenic mice. J Virol 2000;74:4165-4173.

4. Wieland SF, Eustaquio A, Whitten-Bauer C, Boyd B, Chisari FV. Interferon prevents formation of replication-competent hepatitis B virus RNA-containing nucleocapsids. Proc Natl Acad Sci U S A 2005;102:9913-9917.

5. Belloni L, Allweiss L, Guerrieri F, et al. IFN-alpha inhibits HBV transcription and replication in cell culture and in humanized mice by targeting the epigenetic regulation of the nuclear cccDNA minichromosome. J Clin Invest 2012;122:529-537.

6. Visvanathan K, Skinner NA, Thompson AJ, et al. Regulation of Toll-like receptor-2 expression in chronic hepatitis B by the precore protein. Hepatology 2007;45:102-110.

7. Lang T, Lo C, Skinner N, Locarnini S, Visvanathan K, Mansell A. The hepatitis B e antigen (HBeAg) targets and suppresses activation of the Toll-like receptor signaling pathway. J Hepatol 2011;55:762-769.

8. Op den Brouw ML, Binda RS, van Roosmalen MH, et al. Hepatitis $B$ virus surface antigen impairs myeloid dendritic cell function: a possible immune escape mechanism of hepatitis B virus. Immunology 2009;126:280-289.

9. Lütgehetmann M, Bornscheuer T, Volz T, et al. Hepatitis B virus limits response of human hepatocytes to interferon-alpha in chimeric mice. Gastroenterology 2011;140:2074-2083.e2.

10. Boni C, Fisicaro P, Valdatta C, et al. Characterization of hepatitis B virus (HBV)-specific T-cell dysfunction in chronic HBV infection. J Virol 2007;81:4215-4225.

11. Das A, Hoare M, Davies N, et al. Functional skewing of the global CD8 T cell population in chronic hepatitis B virus infection. J Exp Med 2008;205:2111-2124.

12. Micco L, Peppa D, Loggi E, et al. Differential boosting of innate 
and adaptive antiviral responses during pegylated-interferonalpha therapy of chronic hepatitis B. J Hepatol 2013;58:225-233.

13. Thimme R, Dandri M. Dissecting the divergent effects of interferon-alpha on immune cells: time to rethink combination therapy in chronic hepatitis B? J Hepatol 2013;58:205-209.

14. Peppa D, Micco L, Javaid A, et al. Blockade of immunosuppressive cytokines restores NK cell antiviral function in chronic hepatitis B virus infection. PLoS Pathog 2010;6:e1001227.

15. Wong GL, Wong VW, Chan HL. Combination therapy of interferon and nucleotide/nucleoside analogues for chronic hepatitis B. J Viral Hepat 2014;21:825-834.

16. Mutimer D, Naoumov N, Honkoop P, et al. Combination alphainterferon and lamivudine therapy for alpha-interferon-resistant chronic hepatitis B infection: results of a pilot study. J Hepatol 1998;28:923-929.

17. Barbaro G, Zechini F, Pellicelli AM, et al. Long-term efficacy of interferon alpha-2b and lamivudine in combination compared to lamivudine monotherapy in patients with chronic hepatitis B: an Italian multicenter, randomized trial. J Hepatol 2001;35:406-411.

18. Santantonio T, Niro GA, Sinisi E, et al. Lamivudine/interferon combination therapy in anti-HBe positive chronic hepatitis B patients: a controlled pilot study. J Hepatol 2002;36:799-804.

19. Lau GK, Piratvisuth T, Luo KX, et al. Peginterferon Alfa-2a, lamivudine, and the combination for HBeAg-positive chronic hepatitis B. N Engl J Med 2005;352:2682-2695.

20. Janssen HL, van Zonneveld M, Senturk H, et al. Pegylated interferon alfa- $2 \mathrm{~b}$ alone or in combination with lamivudine for $\mathrm{HBeAg}$-positive chronic hepatitis B: a randomised trial. Lancet 2005;365:123-129.

21. Marcellin P, Lau GK, Bonino F, et al. Peginterferon alfa-2a alone, lamivudine alone, and the two in combination in patients with HBeAg-negative chronic hepatitis B. N Engl J Med 2004;351:1206-1217.

22. Marcellin P, Bonino F, Lau GK, et al. Sustained response of hepatitis B e antigen-negative patients 3 years after treatment with peginterferon alpha-2a. Gastroenterology 2009;136:2169-2179.e4.

23. Werle-Lapostolle B, Bowden S, Locarnini S, et al. Persistence of cccDNA during the natural history of chronic hepatitis B and decline during adefovir dipivoxil therapy. Gastroenterology 2004;126:1750-1758.

24. Wursthorn K, Lutgehetmann M, Dandri M, et al. Peginterferon alpha-2b plus adefovir induce strong cccDNA decline and HBsAg reduction in patients with chronic hepatitis B. Hepatology 2006;44:675-684.

25. Piccolo P, Lenci I, Demelia L, et al. A randomized controlled trial of pegylated interferon-alpha2a plus adefovir dipivoxil for hepatitis B e antigen-negative chronic hepatitis B. Antivir Ther 2009;14:1165-1174.

26. Takkenberg RB, Jansen L, de Niet A, et al. Baseline hepatitis B surface antigen ( $\mathrm{HBsAg}$ ) as predictor of sustained HBsAg loss in chronic hepatitis B patients treated with pegylated interferonalpha2a and adefovir. Antivir Ther 2013;18:895-904.
27. Marcellin P, Wursthorn K, Wedemeyer H, et al. Telbivudine plus pegylated interferon alfa-2a in a randomized study in chronic hepatitis B is associated with an unexpected high rate of peripheral neuropathy. J Hepatol 2015;62:41-47.

28. Marcellin P, Ahn SH, Ma X, et al. Combination of tenofovir disoproxil fumarate and peginterferon alpha-2a increases loss of hepatitis B surface antigen in patients with chronic hepatitis B. Gastroenterology 2016;150:134-144.e10.

29. Enomoto M, Tamori A, Nishiguchi S, Kawada N. Combination therapy with a nucleos(t)ide analogue and interferon for chronic hepatitis B: simultaneous or sequential. J Gastroenterol 2013;48:999-1005.

30. Schalm SW, Heathcote J, Cianciara J, et al. Lamivudine and alpha interferon combination treatment of patients with chronic hepatitis B infection: a randomised trial. Gut 2000;46:562-568.

31. Chan HL, Leung NW, Hui AY, et al. A randomized, controlled trial of combination therapy for chronic hepatitis B: comparing pegylated interferon-alpha2b and lamivudine with lamivudine alone. Ann Intern Med 2005;142:240-250.

32. Chan HL, Hui AY, Wong VW, Chim AM, Wong ML, Sung JJ. Long-term follow-up of peginterferon and lamivudine combination treatment in HBeAg-positive chronic hepatitis B. Hepatology 2005;41:1357-1364.

33. Lutgehetmann M, Volzt T, Quaas A, et al. Sequential combination therapy leads to biochemical and histological improvement despite low ongoing intrahepatic hepatitis B virus replication. Antivir Ther 2008;13:57-66.

34. Brouwer WP, Xie Q, Sonneveld MJ, et al. Adding pegylated interferon to entecavir for hepatitis B e antigen-positive chronic hepatitis B: a multicenter randomized trial (ARES study). Hepatology 2015;61:1512-1522.

35. Li GJ, Yu YQ, Chen SL, et al. Sequential combination therapy with pegylated interferon leads to loss of hepatitis B surface antigen and hepatitis B e antigen (HBeAg) seroconversion in HBeAgpositive chronic hepatitis $B$ patients receiving long-term entecavir treatment. Antimicrob Agents Chemother 2015;59:4121-4128.

36. Bourliere M, Rabiega P, Ganne-Carrie N, et al. HBsAg clearance after addition of 48 weeks of pegifn in HBeAg negative CHB patients on nucleos(T)ide therapy with undetectable hbvdna for at least one year: final results from ANRS-HB06 pegan study. Multicenter randomized controlled phase III trial. J Hepatol 2015;62(Suppl 2):S249.

37. Liu CJ, Wang CC, Yang SS, et al. Entecavir plus peginteferon alfa-2a vs. entecavir alone in the treatment of hepatitis B e antigen-positive chronic hepatitis B: an interim report. J Hepatol 2013;58(Suppl 1):S308.

38. Huang Z, Deng H, Zhao Q, et al. Peginterferon-alpha2a combined with response-guided short-term lamivudine improves response rate in hepatitis B e antigen-positive hepatitis B patients: a pilot study. Eur J Gastroenterol Hepatol 2013;25:1165-1169.

39. Wang YX, Zheng SM, Zhang Y, et al. Sustained efficacy of adefovir add-on therapy in chronic hepatitis B patient with a poor 
virological response to peginterferon alfa. Scand J Gastroenterol 2013;48:213-217.

40. Xie Q, Zhou H, Bai X, et al. A randomized, open-label clinical study of combined pegylated interferon Alfa-2a (40KD) and entecavir treatment for hepatitis B "e" antigen-positive chronic hepatitis B. Clin Infect Dis 2014;59:1714-1723.

41. Hou J, Ma H, Sun J, et al. P1067 Response-guided peginterferon alfa-2a (PegIFN alfa-2a) therapy in patients with HBeAg-positive chronic hepatitis b (CHB). J Hepatol 2014;60(1 Suppl):S432-S433.

42. Lampertico P, Viganò M, Di Costanzo GG, et al. Randomised study comparing 48 and 96 weeks peginterferon alfa-2a therapy in genotype D HBeAg-negative chronic hepatitis B. Gut 2013;62:290298.

43. Kumada H, Okanoue T, Onji M, et al. Guidelines for the treatment of chronic hepatitis and cirrhosis due to hepatitis B virus infection for the fiscal year 2008 in Japan. Hepatol Res 2010;40:1-7.

44. Petersen J, Dandri M. Optimal therapy for chronic hepatitis B: hepatitis B virus combination therapy? Liver Int 2015;35 Suppl 1:114-120.

45. Boni C, Laccabue D, Lampertico P, et al. Restored function of HBV-specific T cells after long-term effective therapy with nucleos(t)ide analogues. Gastroenterology 2012;143:963-973.e9.

46. Sarin SK, Sood A, Kumar M, et al. Effect of lowering HBV DNA levels by initial antiviral therapy before adding immunomodulator on treatment of chronic hepatitis B. Am J Gastroenterol 2007;102:96-104.

47. Su WW, Hsu CW, Lee CM, et al. Combination therapy with peginterferon alfa-2a and a nucleos(t)ide analogue for HBeAg-positive chronic hepatitis B patients: results of a large, randomised, multicentre, double-blind, placebo-controlled study. J Hepatol 2014;60(1 Suppl):S47.

48. Ning Q, Han M, Sun Y, et al. Switching from entecavir to PegIFN alfa-2a in patients with HBeAg-positive chronic hepatitis B: a randomised open-label trial (OSST trial). J Hepatol 2014;61:777-784.

49. Hu P, Shang J, Zhang W, et al. Predictive value of baseline and on-treatment qHBsAg level in $\mathrm{HBeAg}$ positive $\mathrm{CHB}$ patients who switched from NUCs to pegylated interferon A-2A: a further analysis from new switch study. J Hepatol 2015;62(Suppl 2):S251.

50. Huang Z, Zhao Z, Zheng Y, et al. Efficacy of sequential use of telbivudine in hepatitis B e antigen-positive chronic hepatitis B patients with partial responses to pegylated interferon: a pilot study. J Viral Hepat 2013;20 Suppl 1:52-57.

51. Piccolo P, Lenci I, di Paolo D, et al. A randomized controlled trial of sequential pegylated interferon-alpha and telbivudine or vice versa for 48 weeks in hepatitis B e antigen-negative chronic hepatitis B. Antivir Ther 2013;18:57-64.

52. Liaw YF. Clinical utility of hepatitis B surface antigen quantitation in patients with chronic hepatitis B: a review. Hepatology 2011;53:2121-2129.

53. Tseng TC, Liu CJ, Su TH, et al. Serum hepatitis B surface antigen levels predict surface antigen loss in hepatitis B e antigen seroconverters. Gastroenterology 2011;141:517-525.e2.
54. Tseng TC, Liu CJ, Yang HC, et al. Determinants of spontaneous surface antigen loss in hepatitis B e antigen-negative patients with a low viral load. Hepatology 2012;55:68-76.

55. Tseng TC, Liu CJ, Yang HC, et al. High levels of hepatitis B surface antigen increase risk of hepatocellular carcinoma in patients with low HBV load. Gastroenterology 2012;142:1140-1149.e3.

56. Brunetto MR, Oliveri F, Colombatto P, et al. Hepatitis B surface antigen serum levels help to distinguish active from inactive hepatitis B virus genotype D carriers. Gastroenterology 2010;139:483490.

57. Chan HL, Thompson A, Martinot-Peignoux M, et al. Hepatitis B surface antigen quantification: why and how to use it in 2011: a core group report. J Hepatol 2011;55:1121-1131.

58. Brunetto MR, Moriconi F, Bonino F, et al. Hepatitis B virus surface antigen levels: a guide to sustained response to peginterferon alfa-2a in HBeAg-negative chronic hepatitis B. Hepatology 2009;49:1141-1150.

59. Chan HL, Wong VW, Chim AM, Chan HY, Wong GL, Sung JJ. Serum HBsAg quantification to predict response to peginterferon therapy of e antigen positive chronic hepatitis B. Aliment Pharmacol Ther 2010;32:1323-1331.

60. Moucari R, Mackiewicz V, Lada 0, et al. Early serum HBsAg drop: a strong predictor of sustained virological response to pegylated interferon alfa-2a in HBeAg-negative patients. Hepatology 2009;49:1151-1157.

61. Su TH, Hsu CS, Chen CL, et al. Serum hepatitis B surface antigen concentration correlates with HBV DNA level in patients with chronic hepatitis B. Antivir Ther 2010;15:1133-1139.

62. Chan HL, Wong VW, Wong GL, Tse CH, Chan HY, Sung JJ. A longitudinal study on the natural history of serum hepatitis B surface antigen changes in chronic hepatitis B. Hepatology 2010;52:12321241.

63. Nguyen T, Thompson AJ, Bowden S, et al. Hepatitis B surface antigen levels during the natural history of chronic hepatitis $\mathrm{B}$ : a perspective on Asia. J Hepatol 2010;52:508-513.

64. Jaroszewicz J, Calle Serrano B, Wursthorn K, et al. Hepatitis B surface antigen (HBsAg) levels in the natural history of hepatitis B virus (HBV)-infection: a European perspective. J Hepatol 2010;52:514-522.

65. Fried MW, Piratvisuth T, Lau GK, et al. HBeAg and hepatitis B virus DNA as outcome predictors during therapy with peginterferon alfa-2a for HBeAg-positive chronic hepatitis B. Hepatology 2008;47:428-434.

66. Zhang X, Lin SM, Ye F, et al. An early decrease in serum HBeAg titre is a strong predictor of virological response to entecavir in HBeAg-positive patients. J Viral Hepat 2011;18:e184-e190.

67. Chan HL, Wong VW, Tse AM, et al. Serum hepatitis B surface antigen quantitation can reflect hepatitis B virus in the liver and predict treatment response. Clin Gastroenterol Hepatol 2007;5:14621468.

68. Yuan Q, Song LW, Liu CJ, et al. Quantitative hepatitis B core antibody level may help predict treatment response in chronic hepati- 
tis B patients. Gut 2013;62:182-184.

69. Yang HC, Kao JH. Looking into the crystal ball: biomarkers for outcomes of HBV infection. Hepatol Int 2016;10:99-101.

70. Tan AT, Hoang LT, Chin D, et al. Reduction of HBV replication prolongs the early immunological response to IFNalpha therapy. J Hepatol 2014;60:54-61.

71. Lucifora J, Xia Y, Reisinger F, et al. Specific and nonhepatotoxic degradation of nuclear hepatitis B virus cccDNA. Science 2014;343:1221-1228.

72. Liu CJ, Lai MY, Chao YC, et al. Interferon alpha-2b with and without ribavirin in the treatment of hepatitis B e antigen-positive chronic hepatitis B: a randomized study. Hepatology 2006;43:742749.

73. Lin CL, Yang HC, Kao JH. Hepatitis B virus: new therapeutic perspectives. Liver Int 2016;36 Suppl 1:85-92.

74. Volz T, Allweiss L, Ben MBarek M, et al. The entry inhibitor Myrcludex-B efficiently blocks intrahepatic virus spreading in humanized mice previously infected with hepatitis B virus. J Hepatol 2013;58:861-867. 